\title{
Workshop dan Pelatihan Social Commerce Untuk Siswa-Siswi Sekolah Menengah Atas Di Surabaya
}

\author{
Alexander Wirapraja ${ }^{1 *}$, Novi Tri Hariyanti ${ }^{2}$ \\ 1* Program Studi Sistem Informasi, Institut Informatika Indonesia, Surabaya, Jawa Timur \\ ${ }^{2}$ Program Studi Manajemen Informatika, Institut Informatika Indonesia, Surabaya, Jawa Timur \\ Email: ${ }^{1}$ awirapraja85@gmail.com, ${ }^{2}$ novi@ikado.ac.id
}

(Naskah masuk: 09 Nov 2021, direvisi: 16 Nov 2021, diterima: 18 Nov 2021)

\begin{abstract}
Abstrak
Social commerce merupakan bentuk metode pemasaran moderen khususnya di Indonesia, lebih dari 60\% masyarakat indonesia adalah pengguna media sosial. Peran informasi memegang peranan penting khususnya melalui konten-konten yang disajikan di media sosial beserta dengan dampak sosial yang menyertainya .Pelatihan dan workshop ini memiliki tujuan untuk meningkatkan kesadaran para anak muda dalam memanfaatkan media sosial tidak hanya sebagai sarana aktualisasi diri namun juga sebagai sarana pemasaran untuk mengembangkan usaha kecil yang berdampak bagi mereka maupun lingkungan sekitar mereka sesuai dengan kemampuan dan minat yang mereka miliki. Peserta yang mengikuti pelatihan ini merupakan para tamu undangan dari tiga sekolah menengah atas di provinsi Jawa Timur. Pelatihan dan workshop ini dilakukan di aula lantai 1 Institut Informatika Indonesia dan rangkaian acara diawali dengan seminar mengenai peran media sosial dalam memanfaatkan jejaring komunitas untuk meningkatkan kualitas dari strategi pemasaran dan dilanjutkan dengan melakukan workshop pada laboratorium desain dan programming yang ada di Institut Informatika Indonesia. Hasil yang didapatkan adalah para siswa antusias dalam mengikuti acara ini terbukti dengan banyaknya pertanyaan yang diajukan dan mereka juga memahami dan mampu untuk menerapkan konsep pemasaran dengan menggunakan media sosial pada area lingkungan mereka masing-masing sesuai dengan bidang dan kompetensi yang dikuasai.
\end{abstract}

Kata Kunci: Social Commerce, Media Sosial, Seminar, Workshop

\section{Social Commerce Workshop and Training for High School Students in Surabaya}

\begin{abstract}
Social commerce is a form of modern marketing method, especially in Indonesia, more than $60 \%$ of Indonesian people are social media users. The role of information plays an important role, especially through the content presented on social media along with the accompanying social impact. This training and workshop has the aim of increasing awareness of young people in using social media not only as a means of self-actualization but also as a marketing tool to develop small businesses that have an impact on them and the environment around them according to their abilities and interests. Participants who took part in this training were invited guests from three high schools in East Java province. This training and workshop was conducted in the 1 st floor hall of the Institut Informatika Indonesia and the series of events began with a seminar on the role of social media in utilizing community networks to improve the quality of marketing strategies and continued by conducting workshops in the design and programming laboratory at the Institute Informatika Indonesia. The results obtained are that students feel enthusiastic in participating in this event as evidenced by the many questions asked and they also understand and are able to apply marketing concepts using social media in their respective environmental areas according to the fields and competencies mastered.
\end{abstract}

Keywords: Social Commerce, Social Media, Seminar, Workshop 


\section{PENDAHULUAN}

\section{A. Latar Belakang}

Indonesia sebagai salah satu negara dengan jumlah populasi penduduk terbanyak di dunia juga memiliki jumlah pengguna internet yang cukup besar. Penduduk indonesia berdasarkan data dari WeAreSocial pada bulan Januari tahun 2021 [1] tercatat sebesar 274,9 Juta penduduk dengan sebaran pengguna internet sebesar 202,6 juta penduduk atau bila dibandingkan dengan jumlah penduduk secara presentase adalah sebesar $73,7 \%$. Data penguna internet tersebut saat ini menurut data dari BPS dikutip oleh kompas.com menurut data pada bulan januari 2021 didominasi oleh generasi $\mathrm{Z}$ dan generasi milenial, generasi $\mathrm{z}$ memiliki komposisi sebesar $27,94 \%$ dari jumlah penduduk dan generasi milenial sebesar $25,87 \%$ [2]. Jumlah ini tidak mengherankan bila dilihat bahwa pemanfaatan media sosial sebagian besar didominasi baik pria maupun wanita oleh rentang umur 18-24 tahun sebesar 30,7\% dan umur 25-34 tahun sebesar 34,1\% [1].

Beberapa perusahan dan merek ternama pun telah mengembangkan saluran pemasaran mereka dari konvensional menjadi berbasis digital dengan memanfaatkan media sosial sebagai contoh adalah Starbuck yang sejak 2013 telah membaca potensi dari pemanfaataan media digital khususnya media sosial sebagai strategi pemasaran yang efektif. Starbucks mulai berinteraksi dengan pelanggan melalui situs webnya sendiri Starbucks.com di mana pelanggan dapat mengajukan dan memberikan saran mereka dengan tujuan untuk meningkatkan citra merek dari perusahaan dan Starbuck juga mengembangkan jaringan komunitas mereka juga melalui situs media sosial lain seperti Facebook, situs microblogging Twitter, Instagram dan situs video blog seperti YouTube. Starbucks kemudian menjadi salah satu merek Facebook yang paling 'disukai' dan salah satu merek yang memiliki banyak pengikut di Twitter [3]. Lingkungan pemasaran dengan memanfaatkan media sosial adalah dengan menciptakan konten yang kreatif dan menarik, konten-konten ini akan mendorong interaksi dan partisipasi pengguna dengan demikian ketika menjelajahi situs web, pengguna akan dipengaruhi oleh multimedia situs web, interaksi konten, dan informasi konten [4].

Peluang cukup besar bagi negara untuk mengembangkan perekonomian mengingat generasi z dan milenial memiliki potensi mampu beradaptasi dengan cepat terhadap perubahan teknologi dan memiliki potensi menjadi kreator handal dari sebuah konten kreatif. Melihat dari peluang yang ada inilah menjadikan Insititut Informatika Indonesia (IKADO) ingin melakukan pemberian workshop dan pelatihan bagi para siswa yang masih mengenyam pendidikan di bangku sekolah menengah atas agar mampu menjadi individu yang tangguh dan memiliki daya kreatifitas yang baik sesuai dengan visi misi institusi dalam menciptakan pribadi yang memiliki jiwa technopreneuship dan siap bersaing di industri dan pasar global.

\section{B. Media Social}

Media sosial adalah teknologi berbagi konten yang memungkinkan pengguna untuk membuat, membagikan, menerima dan menyimpan konten tersebut. Bentuk konten pada media sosial dapat berupa blog, video blog (vlog), video sharing, ulasan secara daring sebagai bentuk aktualisasi diri baik secara pribadi maupun kelompok [5]. Beberapa data pribadi yang sering di inputkan oleh pengguna kepada media sosial adalah seperti pada tabel 1 berikut ini:

Tabel 1. Data Pengguna Berdasarkan Tipe Media Sosial [6]

\begin{tabular}{|c|c|}
\hline $\begin{array}{c}\text { Platform } \\
\text { Media Sosial }\end{array}$ & Contoh Data Pengguna \\
\hline Facebook & $\begin{array}{l}\text { FacebookID, nama, link profil, alamat, } \\
\text { deskripsi, pekerjaan, tempat dan detil } \\
\text { pendidikan (masuk, lulus, jurusan dan lain- } \\
\text { lain), jenis kelamin, zona waktu, bahasa, } \\
\text { daftar pertemanan, timeline, gambar, video, } \\
\text { notes, dan events }\end{array}$ \\
\hline Twitter & $\begin{array}{l}\text { UserID, konten (tweets, timeline, hashtag, } \\
\text { pesan pribadi), jumlah tweet/retweet, } \\
\text { hubungan antar pengguna (follower, } \\
\text { following, blocked, ignored), tren terbaru } \\
\text { (berdasarkan lokasi, negara, jarak) }\end{array}$ \\
\hline LinkedIn & $\begin{array}{l}\text { UserID, nama pengguna, nama perusahaan, } \\
\text { tanggal lahir, profil pengguna, lokasi, } \\
\text { sektor industri, posisi, gambar, } \\
\text { kemampuan, sertifikasi, pelatihan, konten } \\
\text { (current share, gambar, catatan profil } \\
\text { profesional), koneksi antar pengguna }\end{array}$ \\
\hline Instagram & $\begin{array}{l}\text { UserID, data pengguna, konten (feed, story, } \\
\text { reels), jumlah likes, jumlah komentar, relasi } \\
\text { (jumlah follower dan following), data } \\
\text { mengenai konten (lokasi, hashtag, } \\
\text { komentar, jumlah viewer) }\end{array}$ \\
\hline
\end{tabular}

Data-data seperti contoh pada tabel 1 ini yang dapat digunakan sebagai sarana pengambilan keputusan bagi perusahaan dalam menentukan sasaran dan target pasar mereka saat memutuskan memilih dan menggunakan salah satu platform diatas sebagai saluran pemasaran online.

Pelaksanaan workshop dan pelatihan ini juga memiliki tujaun memberikan pengetahuan dan wawasan kepada siswa dan siswi mengenai dampak positif dan negatif dari transparansi data, ada beberapa data dan informasi yang dapat dibagikan melalui media sosial namun ada pula yang tidak.

\section{Social Commerce}

Social Commerce didefinisikan sebagai bentuk peristiwa atau proses pemasaran komersial yang menggunakan media sosial dalam upaya untuk mempengaruhi secara positif perilaku pembelian konsumen [4]. Definisi lain dari social commerce menyebutkan bahwa social commerce adalah $e$ commerce yang dikemas dalam bentuk jaringan sosial dan hubungan sosial secara daring [7].

Secara umum konsep social commerce tidak lepas dari peran komunitas didalamnya. Informasi mengenai sebuah produk dapat dikomunikasikan dan dibagikan secara langsung kepada pengguna lain, konsep ini dikenal dengan nama EWOM. E-WOM atau (electronic word of mouth) secara definisi merupakan pengalaman pribadi yang dinyatakan 
dalam bentuk hasil evaluasi, diskusi, dan rekomendasi pengguna terhadap produk yang digunakan dan disebarluaskan oleh konsumen melalui media online [8].
Hubungan interaksi antara social commerce dan ecommerce menurut penelitian dari Gibreel, dkk tahun 2018 memaparkan hubungan tersebut melalui gambar 1 berikut ini:

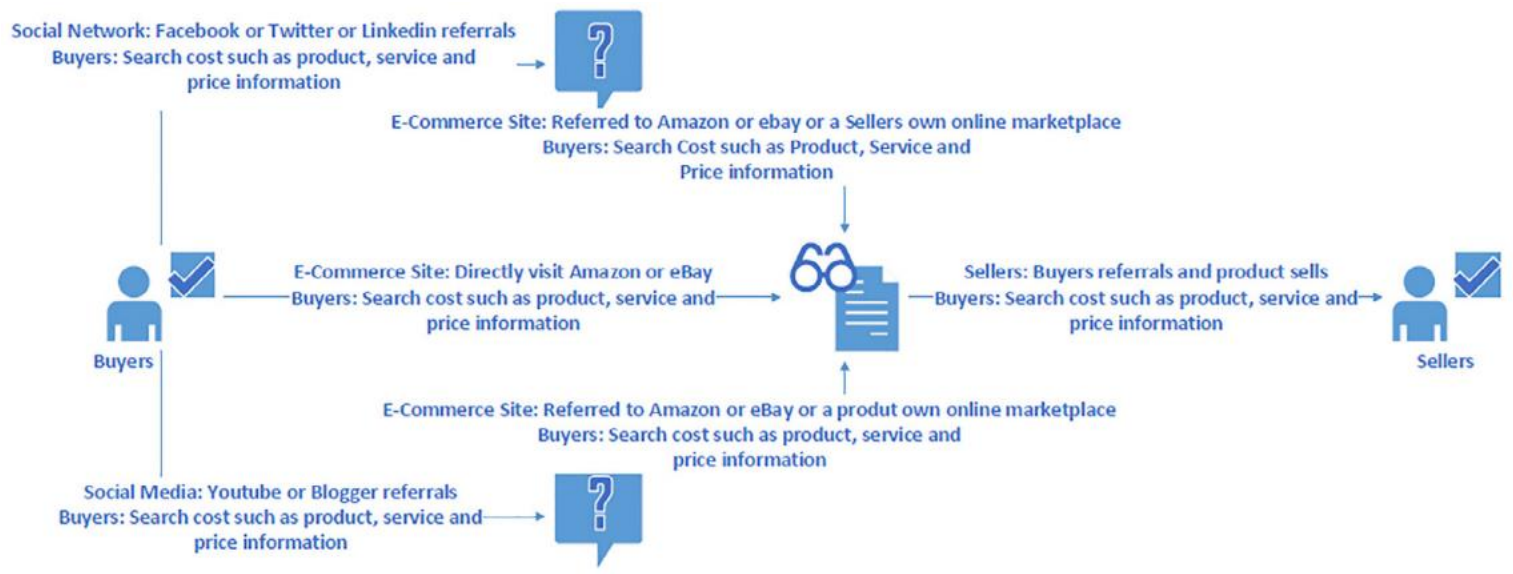

Gambar 1. Interaksi Social Commerce dalam Marketplace [7]

Tantangan yang dihadapi pemasaran yang memilih menggunakan media sosial dalam strategi pemasarannya untuk mencapai kepuasan pelanggan adalah adanya kemampuan untuk menyatukan harapan maupun ekspektasi pelanggan, kebutuhan individu, pengalaman paska pembelian, rekomendasi dari pihak ketiga, dan penyedia layanan periklanan [9].

Melalui pelatihan dan workshop ini juga dijelaskan tantangan dan permasalahan yang dihadapi oleh pengguna media sosial dalam memasarkan produk mereka beserta dengan solusi yang dapat digunakan baik untuk para peserta yang memiliki keinginan untuk memiliki usaha atau yang sudah memiliki atau melanjutkan usaha yang telah dijalankan saat ini.

\section{METODE KEGIATAN}

Untuk mencapai tujuan yang diharapkan yaitu memberikan pengetahuan dan wawasan kepada para peserta kegiatan yang dalam hal ini adalah para siswa-siswi dari SMA undangan yang ada di Jawa Timur, kegiatan ini juga bertujuan sebagai bentuk dari implementasi kegiatan pengabdian masyarakat oleh para tim dosen dari Institut Informatika Indonesia. Beberapa tahapan dalam kegiatan ini adalah sebagai berikut:

a. Tahap Perencanaan

Pada tahap perencanaan dilakukan pemetaan terhadap para undangan yaitu para peserta seminar, dalam hal ini adalah para siswa-siswi dari SMA di Jawa Timur. Pada tahap perencanaan juga dilakukan pencarian tanggal pelaksanaan seminar dengan melihat data dari peserta yang sebelumnya telah memberikan konfirmasi kepada pihak Institut Informatika Indonesia.

b. Tahap Pelaksanaan Seminar

Seminar ini mengusung tema Social Commerce: The Power of Thumbs Up. Sedangkan untuk pembicara seminar atau panelis dan moderator dalam acara seminar dan workshop ini adalah para dosen dari Institut Informatika
Indonesia pembicara merupakan dosen dari fakultas teknologi informasi, sedangkan untuk tempat untuk pelaksanaan seminar bertempat di aula lantai 1 Institut Informatika Indonesia Surabaya.

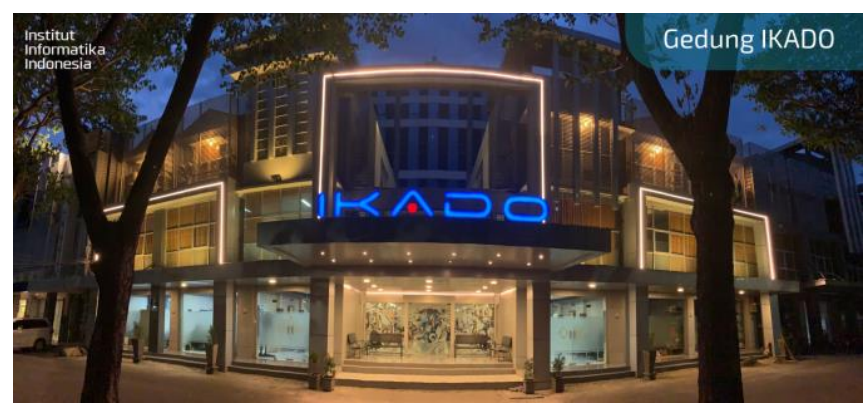

Gambar 2. Institut Informatika Indonesia [10]

c. Tahap pelaksanaan Workshop

Setelah seminar berakhir maka tahap selanjutnya adalah pelaksanaan workshop yang bertempat di laboratorium komputer di Institut Informatika Indonesia, tahapan ini bertujuan agar para peserta dapat mencoba secara langsung langkah-langkah dalam pembuatan produk yang inovatif dan mendapatkan bimbingan langsung dari para dosen yang berada di tiap laboratorium

d. Tahap Evaluasi Kegiatan

Pada tahap evaluasi kegiatan dilaksanakan setelah acara selesai dengan melakukan rapat evaluasi singkat untuk membahas kelebihan dan kekurangan dari penyelenggaraan acara, pada tahap ini diikuti oleh seluruh panitia acara baik panitia staf dan dosen maupun panitia mahasiswa.

Hasil atau luaran yang diharapkan dari pelaksanaan kegiatan seminar dan workshop ini adalah:

1. Para siswa mampu memahami dengan mendapatkan pengetahuan mengenai potensi dari pemanfaatan media sosial dalam dunia pemasaran 
2. Sebagai sarana untuk mengenalkan metode dan tren industri terkini kepada siswa

3. Para siswa mampu mengembangkan ide untuk menciptakan konsep produk yang terbaru dan inovatif dengan memanfaatkan media sosial

\section{PELAKSANAAN KEGIATAN}

Pelaksanaan Kegiatan dilakukan selama satu hari dari pukul 10.00 hingga 15.00. Peserta pada kegiatan ini diikuti oleh kurang lebih sekitar 137 peserta yang telah memberikan konfirmasi kehadiran kepada pihak IKADO Surabaya. Seluruh peserta seminar dan workhop yang hadir terdiri dari 3 Sekolah Menengah Atas (SMA) dengan rincian peserta adalah SMK Petra Surabaya, SMU Katolik Thomas Aquino Tulung Agung dan SMU Katolik St. Agustinus Kediri.

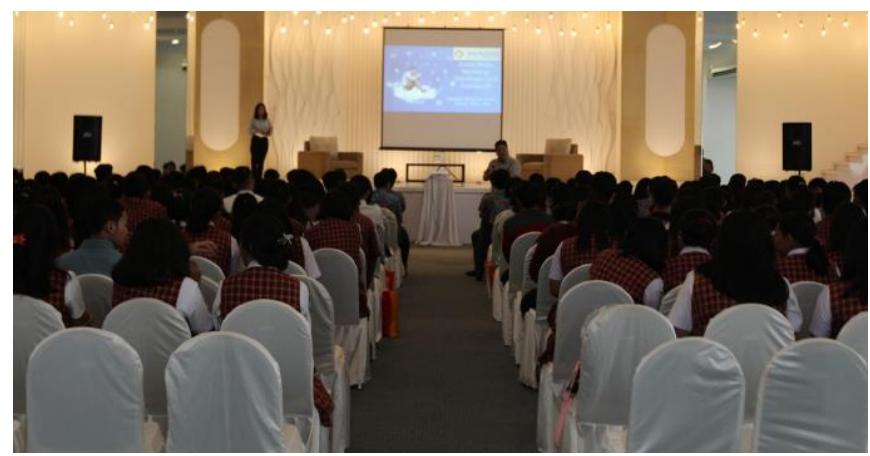

Gambar 3. Pelaksanaan Seminar

Urutan kegiatan dari pelaksanaan seminar dan workshop ini adalah sebagai berikut:

1. Pembukaan dan pengenalan Institut Informatika Indonesia (IKADO) Surabaya

2. Sambutan rektor dan pembukaan acara

3. Pengelanan moderator dan panelis seminar

4. Pelaksanaan seminar Social Commerce: The Power of Thumbs Up

5. Sesi tanya jawab dan pelaksanaan quiz

6. Pembagian kelompok siswa dan diarahkan ke setiap laboratorium yang telah ditentukan

7. Pelaksanaan workshop pada laboratorium komputer IKADO Surabaya

8. Pengumuman pemenang quiz dan sesi foto bersama

9. Penutupan

Ringkasan dari materi yang disampaikan pada saat seminar ini meliputi:

1. Konsep dan definisi social commerce

2. Perbedaan Social Commerce dan E-Commerce

3. Keuntungan dan kerugian dari pemanfaatan social commerce

4. Metode dan perbedaan dari setiap aplikasi media sosial

5. Konsep perilaku konsumen digital dan tren masyarakat pengguna media sosial

6. Mengembangkan fitur monetisasi pada apikasi social commerce.
7. Proses promosi dan perngembangan produk yang kreatif dan inovatif dengan memanfaatkan media sosial.

8. Konsep berbagi komunitas dan dampak dari implementasi variabel E-WOM terhadap konten yang di bagikan didalam media sosial.

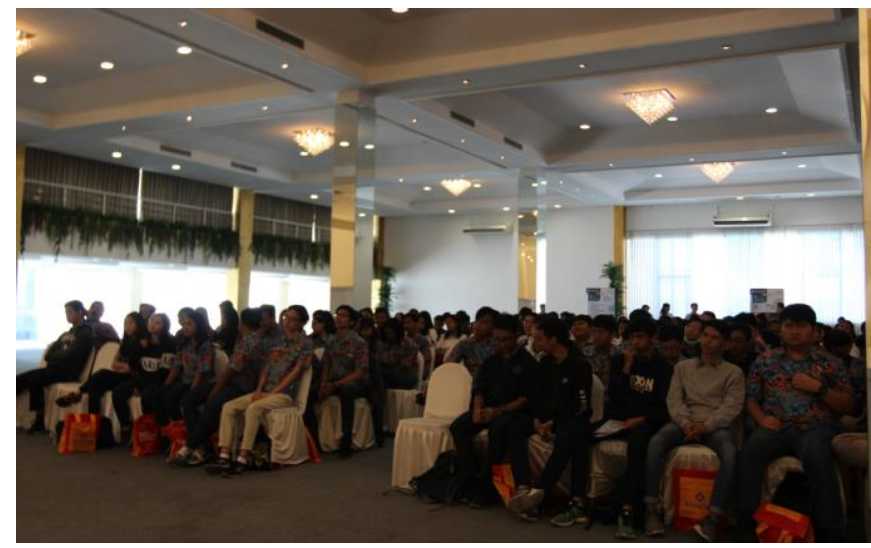

Gambar 4. Dokumentasi Peserta Seminar

Setelah peserta selesai mengikuti seminar berikutnya adalah dilakukan pembagian peserta menjadi kelompokkelompok kecil untuk dilakukan demo praktikum programming dan desain pada laboratorium yang telah ditentukan. Adapun pelaksanaan workshop ini dipandu oleh para dosen dari setiap laboratorium dibantu oleh tim mahasiswa Institut Informatika Indonesia sebagai pendamping.

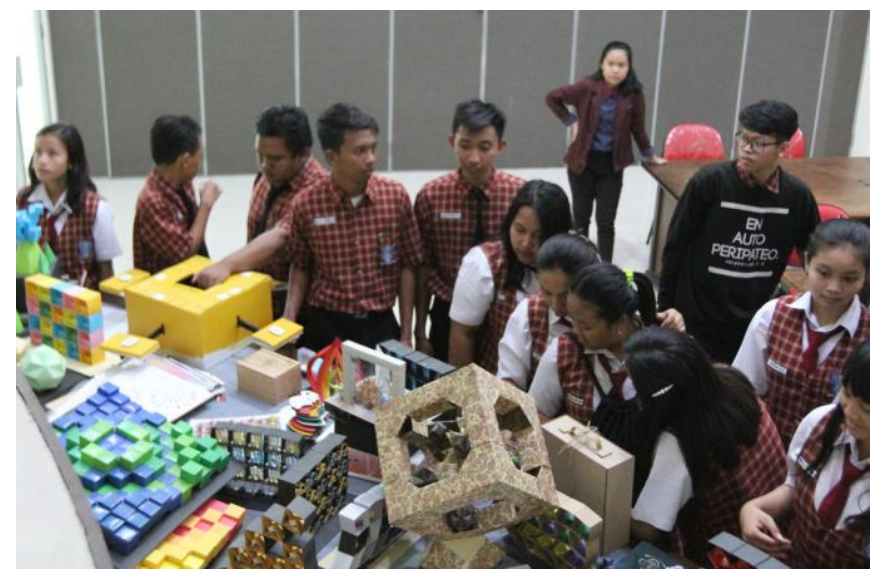

Gambar 5. Dokumentasi Peserta Workshop

Pada sesi workshop ini dilakukan demo dan tutorial singkat oleh dosen koordinator yang bertugas di setiap laboratorium kemudian memberikan kesempatan kepada para siswa untuk mencoba langsung dan melakukan observasi langsung terhadap proses perancangan produk, detil dan sepesifikasi produk, bahan-bahan dan metode yang digunakan. Pada sesi workshop dilaboratorium ini juga diberikan sesi diskusi secara interaktif agar para siswa dapat memahami secara langsung proses-proses perancangan dan pengembangan produk yang ada. 


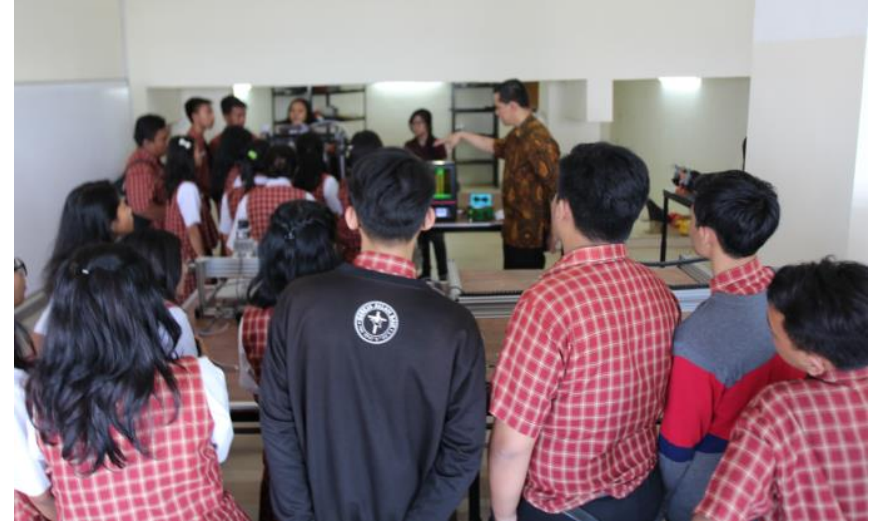

Gambar 6. Workshop pada laboratorium Desain 3D

Pada pelaksanaan kegiatan baik seminar maupun pelaksanaan workshop dilaboratorium dapat terlihat semangat dan antusiasme peserta dalam mengikuti acara tersebut, hal ini terbukti dari keaktifan peserta dalam mencoba dan bertanya kepada dosen koordinator laboratorium selama pelaksanaan workshop dan seminar.

\section{KESIMPULAN}

Kegiatan ini merupakan bagian dari komitmen dari Institut Informatika Indonesia dalam rangka untuk meningkatkan kualitas dari Sumber daya manusia khususnya generasi millenial dalam memahami penggunaan media sosial. Pelaksanaan seminar ini dilakukan kepada tamu undangan yaitu dari tiga sekolah di Jawa Timur dan dilanjutkan dengan sesi workshop sebagai implikasi dari materi yang telah diberikan.

Pemilihan tema media sosial adalah karena media sosial dipandang sebagai salah satu metode yang baik dalam melakukan pemasaran khususnya bagi tenaga pemasar pemula yang mengalami kesulitan dalam memasarkan produk mereka. Kesulitan para pemasar muda adalah karena kurangnya modal yang tersedia untuk melakukan promosi terhadap produk dan keterbatasan lingkup komunitas sebagai sarana berbagi dalam memasarkan produk mereka.

\section{UCAPAN TERIMAKASIH}

Secara khusus ucapan terimakasih kami sampaikan kepada pihak Institut Informatika Indonesia yang telah memberikan fasilitas agar acara ini dapat terselenggara dengan baik dan juga para tamu undangan khususnya para kepala sekolah dan jajarannya yang telah bersedia hadir dan memenuhi undangan kami demi terselenggaranya dengan baik acara ini.

\section{REFERENSI}

[1] S. Kemp, "Digital 2021: Indonesia," Kepios Pte. Ltd., We Are Soc. Ltd., Hootsuite Inc., 2021, [Online]. Available: https://datareportal.com/reports/digital2021-indonesia.

[2] Kompas, "Indonesia Didominasi Generasi Milenial dan Generasi Z, Apa Plus Minusnya?," kompas.com, 2021. .

[3] I. Perepu, "Starbucks : Brewing Customer Experience through Social Media," IBS Cent. Manag. Res., vol. 44, no. 0, pp. 1-19, 2013, [Online]. Available: http://www.bu.edu/goglobal/a/goglobal_courses/tm6 48/spain/starbucks.pdf.

[4] S. C. Chen and C. P. Lin, "Understanding the effect of social media marketing activities: The mediation of social identification, perceived value, and satisfaction," Technol. Forecast. Soc. Change, vol. 140, no. November 2018, pp. 22-32, 2019, doi: 10.1016/j.techfore.2018.11.025.

[5] D. Boddy, Management An Introduction, 7th ed. Pearson, 2017.

[6] A. Charlesworth, Social customer relationship management. 2018.

[7] O. Gibreel, D. A. AlOtaibi, and J. Altmann, "Social commerce development in emerging markets," Electron. Commer. Res. Appl., vol. 27, pp. 152-162, 2018, doi: 10.1016/j.elerap.2017.12.008.

[8] Y. Zhao, L. Wang, H. Tang, and Y. Zhang, "Electronic word-of-mouth and consumer purchase intentions in social e-commerce," Electron. Commer. Res. Appl., vol. 41, no. May 2019, p. 100980, 2020, doi: 10.1016/j.elerap.2020.100980.

[9] A. Wirapraja and A. P. Subriadi, "Effectiveness of Social Commerce in Influencing Repurchase Intention: A Systematic Literature Review," Proc. 2019 Int. Conf. Comput. Sci. Inf. Technol. Electr. Eng. ICOMITEE 2019, vol. 1, pp. 24-29, 2019, doi: 10.1109/ICOMITEE.2019.8921184.

[10] R. Basatha, D. S. O. Soedargo, and A. Wirapraja, "Workshop Pelatihan Learning Management System Secara Online Dengan Menggunakan Google Classroom Untuk Guru SMAK St. Albertus, Malang.," Komatika J. Pengabdi. Kpd. Masy., vol. 1, no. 1 , pp. 24-28, 2021, doi: 10.34148/komatika.v1i1.369. 